\title{
The asymmetric and multi-scale volatility correlation between global oil price and economic policy uncertainty of China
}

\author{
Qisheng Jiang ${ }^{1}(\mathbb{D})$ Sheng Cheng ${ }^{1,2} \cdot$ Yan Cao $^{1} \cdot$ Zicheng Wang $^{3}$ \\ Received: 2 March 2021 / Accepted: 5 September 2021 / Published online: 17 September 2021 \\ (C) The Author(s), under exclusive licence to Springer-Verlag GmbH Germany, part of Springer Nature 2021
}

\begin{abstract}
With the monthly data of WTI oil price and economic policy uncertainty (EPU) of China from January 2000 to August 2020, this paper detailedly investigates the asymmetric volatility correlations between two types of EPU of China and global oil price in different time scales. The empirical results demonstrate that the volatility correlation between EPU of China and West Texas Intermediate (WTI) oil price is mainly reflected in the monetary policy uncertainty (MPU), while that of fiscal policy uncertainty (FPU) is much weaker. Specifically speaking, the volatility correlation between MPU of China and downward WTI oil price is significantly negative in the short-middle term (4-8 months) and changes to positive in the middle-long term ( $8-16$ months), while that of upward WTI oil price is only significantly positive in the long term (16-32 months). Our findings provide a deeper understanding of the oil price-EPU correlation in China, and can be valuable guidance for diversified market participants such as government policy-makers and global investors.
\end{abstract}

Keywords Economic policy uncertainty $\cdot$ Oil price $\cdot$ Volatility $\cdot$ China $\cdot$ Asymmetric $\cdot$ Multi-scale

\section{Introduction}

Crude oil is one of the most important commodities, and its price has long been regarded as a vital factor to influence the macroeconomic fluctuation and financial stabilization (Cheng and Cao 2019; Hamilton 1983; Trung 2019). In particular, the oil price war and resulting global oil price crash in the first half of 2020 directly lead to US stock price's sharp reduction, which even triggered the "circuit-breaker" mechanism five times in just half a month! When facing the macroeconomic fluctuation caused by violate oil price shock, the concept of economic policy uncertainty (EPU) caught scholars' attention once again after the 2008 global financial crisis. Actually, the

Responsible Editor: Philippe Garrigues

Sheng Cheng

chengsheng@cug.edu.cn

1 Economics and Management College, China University of Geosciences, 430074 Wuhan, China

2 No. 68 Jincheng Street, East Lake High-tech Development Zone, Wuhan, China

3 Wuhan Hengtai Hongan Safety Technology Co., Ltd, 430074 Wuhan, China close connection between oil price and EPU has been discussed by a series of previous literature. On the one hand, the impact of EPU on oil price can be transmitted via declines in growth, investment, and demand (Antonakakis et al. 2014; Jones and Olson 2013). On the other hand, the oil price shocks can be propagated to economy through macroeconomic policies such as fiscal policy (Pieschacón 2012). To maintain the economic stability and growth, policy-makers might face the trade-off between high inflation and low production output stabilization (Montoro 2012; Sun et al. 2020), and these adjustments of macroeconomic policy will inevitably affect the EPU.

To be specific, the two most traditional and influential macroeconomic tools, fiscal policy and monetary policy, are also the most important policy adjustment objects (Baker et al. 2016; Cheng et al. 2019). Since different macroeconomic policies usually have different functions and work in different periods, there connections with external oil price shock may also vary (Xue et al. 2020). For example, oil price shock has been verified as an important factor to affect the long-term fiscal policy of oil-exporting countries (El Anshasy and Bradley 2012), while a large amount of literature have noticed and discussed its close and direct connection with monetary policy (e.g., Kim et al. 2017; Liu et al. 2015; Shangle and Solaymani 2020). Therefore, when the nexus between oil 
price shock and macroeconomic policy fluctuation has become a research hotspot in recent years, this paper suspects that the uncertainty of fiscal policy and monetary policy may have different correlations with external oil price shock.

Unlike most existing researches which focus on the oil price-EPU linkage in the USA (e.g., Kang et al. 2017; Qin et al. 2020; Zhang and Yan 2020) or other oil-exporting economies (e.g., Koh 2017; Naifar et al. 2020), our attention is paid on China because of the following reasons. Firstly, China is the largest developing country and important driving force sources of global economic recovery (Zhang et al. 2019); there is great significance to figure out how China's policy uncertainty responds to global oil price shock (Xue et al. 2020; You et al. 2017), especially when global economy is witnessing a huge disaster. Secondly, China has become the second largest oil consumer since 2003, and according to 2019 BP Statistical Review of World Energy, China's net imports of crude oil and refined oil first broke 500 million tons and 50 million tons marks in 2019; meanwhile, foreign dependence of them both surpass $70 \%$ and far higher than the internationally recognized security line $50 \%$. ${ }^{1}$ China is mostly acting as an accepter and responder to external oil price shock compared with the USA (Cheng et al. 2019), which largely highlights the necessity for China to adjust the fiscal policy and monetary policy when facing global oil price shock (Wei 2019). Thirdly, energy saving and pollution emission have been regarded as two urgent economic tasks and local political targets of China in recent years (Jiang et al. 2020; Tang et al. 2021); it is suspected that the nexus between China's macroeconomic adjustment and energy price volatility might be different from other developed countries.

Given the possible asymmetric impact of oil price volatility and complexity of real market, we attempt to figure out the oil price-EPU volatility correlations in different oil price change directions and different time scales. On the one hand, obvious asymmetries have been witnessed and verified in the response of economic activity to oil price increase and decrease (Herrera et al. 2015; Kocaarslan et al. 2020). Since crude oil is one of the most important industrial fuels, the change of its price has direct linkage with the production activity (Zhu and Chen 2019). Previous literatures have proved that the GDP (Gross Domestic Production) will decrease with the increase of oil price, while the reduced oil price does not necessarily attach with the GDP increase (Das and Kannadhasan 2020). Likewise, the policy responses of China to upward or downward oil price are likely to be asymmetric as well. On the other hand, the real financial market is complicated and consists of a variety of market participants with different decision-making preferences (Huang et al. 2016), including investors, manufacturers, and government policy-makers. When making

\footnotetext{
${ }^{1}$ News can be accessed at http://center.cnpc.com.cn/sysb/system/2020/03/13/ 001766599.shtml.
}

decisions on investment, production, or policy-making, these market participants usually care about oil price fluctuations over different circles (Sun et al. 2020). For example, the financial speculators mostly care about their shortterm portfolio, while the government policy-makers have to mane balanced decision between the short-term and long-term targets.

The monthly data of WTI oil price and China's FPU and MPU indices in the period of January 2000 to August 2020 is employed in the empirical analysis section. With the raw data, the returns of them are calculated so as to divide all samples into two groups according to their change direction, and the squared returns are used to describe their volatility. Then, using maximum overlap discrete wavelet transformation (MODWT) method, the entire volatility series is separated into five time scales ( $2-4$ months, $4-8$ months, $8-16$ months, 16-32 months, and 32+ months). For the last step, since Bayesian estimators using a certain type of noninformative priors showed higher accuracies than the other Bayesian estimators (Ni and Sun 2005), a vector autoregressive (VAR) model using the full Bayesian estimation is adopted to investigate how China' FPU and MPU volatility interact with the WTI volatility in two oil price change groups and five time scales, respectively. Our empirical results detailed expose that the volatility correlations between WTI oil price and EPU of China vary with different types of policy uncertainty, oil price change directions, and time scales.

This paper contributes to the existing researches in at least the following three aspects. First, although latest literature has separately noticed the asymmetric influence of oil price shock and the oil price-EPU interactions in the short or long term (e.g., Lin and Bai 2021; Sun et al. 2020), to the best of our knowledge, this paper is the first to expose the asymmetric and multi-scale volatility correlation between different types of EPU of China and global oil price at the same time. Second, on the basis of NARDL (nonlinear autoregressive distributed lag) model put forwarded by Shin et al. (2014), we employ a MODWT approach to remove noise and explore the symmetric volatility correlation in different time scales rather than just the short term and long term (Khraief et al. 2021), so that a more detailed understanding can be obtained. Third, our empirical results provide new and solid evidence that the volatility of MPU rather than FPU of China has strong correlation with WTI oil price volatility, and this correlation varies with different oil price change directions. We hold that these findings are important expansions for researches on the connection between macroeconomic policy adjustment and global oil price fluctuation.

The remainder of this paper is arranged as below: the "Literature review" section provides the detailed review of related literature; the "Data and methodology" section is the data description and methodology, as well as the framework of empirical researches; the "Empirical results" section 
displays the main results of a series of empirical tests and relevant discussions; in the last section, we summarize our main conclusions and findings.

\section{Literature review}

As one of the most crucial fossil fuels and industrial materials, the price fluctuation of crude oil has long been attached with the macroeconomic activity and spurred many academic researches and market participants (Yang 2019). Since Hamilton (1983) proposes that oil price shock was an important factor that caused economic recession of the USA and may account for much of post-OPEC macroeconomic performance, the connection between oil price fluctuation and the macroeconomy has been attracting an increasing number of scholars. For example, Peter Ferderer (1996) provides empirical support for the proposition that oil price shocks may have an adverse impact on the macroeconomy because of both oil price level and oil price volatility. Jarrett et al. (2019) find that oil price volatility can adversely affect the growth and volatility of economy inspired by the dramatic decline of oil prices in 2014. van Eyden et al. (2019) verify the significant negative effect that oil price volatility has on the economic growth of 17 OECD countries, especially for the oilproducing countries such as Canada and Norway. Maheu et al. (2020) conclude that there exists a strong volatility link between the oil price and real economic growth.

In the meanwhile, some researches notice that the impact of oil price change is asymmetric and varies with different change directions. Peltzman (2000) points out that the asymmetry of commodity price change is ubiquitous rather than accidental. Using the copulas model to characterize dependence between oil and metal price returns, Reboredo and Ugolini (2016) find that large downward and upward oil price movements had spillover effects on all these metals both before and after the outbreak of the global financial crisis. With the help of quantile regression approach, You et al. (2017) empirically examine the asymmetric effects of oil price shocks and economic policy uncertainty, and these effects are highly related to stock market conditions. Empirical evidence of Kocaarslan et al. (2020) indicates that reduced oil price uncertainty can lead to unemployment decrease, while the impact of oil price uncertainty increase is insignificant. In recent years, the NARDL model gradually become a popular tool to analyze the asymmetric impact of oil price fluctuation after it is proposed by Shin et al. (2014). For example, Zhu and Chen (2019) use the NARDL model to capture the asymmetries of the long-run effects from the positive and negative changes of oil price and exchange rate. Using the NARDL model to decompose oil price into negative and positive changes, Akinsola and Odhiambo
(2020) empirically examine the asymmetric effect of oil price on economic growth in both the long and short run.

Since firstly highlighted by Bloom (2009), EPU has been gradually acknowledged as important indicator in describing the stability of macroeconomy (Huang and Luk 2020; Qin et al. 2020); therefore, its connection with oil price fluctuation has been attracting more and more researchers' interest. For example, with the monthly data of USA from January 1985 to December 2011, Kang and Ratti (2013) reveal the significant association between increases of the real oil price and EPU, and the structural oil price shocks will have long-term impact on EPU. Using the monthly data of China from January 1995 to December 2011, Kang and Ratti (2015) empirically investigate and examine the interdependence of global oil market, China's stock market, and EPU returns, and find that the positive shock of EPU in China has a negative impact on global oil production and price. With the daily data in the period of 1986 to 2017, Mei et al. (2019) hold that MPU has significantly positive impact on oil volatility and can be used to predict oil market fluctuation together with EPU. By incorporating the wavelet approach into the structural vector autoregression (SVAR), Yang (2019) finds that crude oil prices are more like to be the receivers of EPU information but not the driving factor, among which the EPU of USA plays an increasingly vital role. The latest research of Lin and Bai (2021) discusses the asymmetric impact of oil price shock on global EPU.

In recent year, some researches become aware of the significance and necessity of studying oil price-EPU correlation in time-frequency domains. For example, with the help of a time-frequency decomposition approach, Uddin et al. (2018) explore the casual interrelationships between oil market and geopolitical, economic, and financial uncertainty indices. Using a methodology consists of discrete wavelet transform (DWT) and VAR model to explore the impact of oil price shocks on EPU from a multi-scale perspective, Chen et al. (2020) conclude that the effects of oil price shocks on EPU are time-varying over different time scales. With the help of wavelet transformation and linear Granger causality tests, Sun et al. (2020) empirically explore the causality and comovement of EPU indices and WTI oil prices of ten major economies in time-frequency domains. Jiang and Cheng (2021) detailedly investigate the volatility correlation between oil price and EPU of China in different time scales, and diversified findings are acquired.

Overall, the oil price-EPU connection has become a more and more popular topic, and frontier researches have realized the significance to study this topic in symmetric and multiscale perspective. However, we hold there still exist some gaps to be filled. Firstly, most researches regarded as the EPU as a whole, while rarely notice the difference between different types of economic policy. Secondly, most existing literature about oil-EPU focuses on the USA or other developed countries, while that of China requires much more supplement, and the necessity of which is highlighted because of 
recent global economic recession. Lastly, latest researches have separately studied the oil price-EPU correlation in symmetric or multi-scale perspective, but ignoring that their multiscale correlation may vary in different oil price change directions. In this context, this paper attempts to fill the gaps in these aspects.

\section{Data and methodology}

\section{Data}

To specifically investigate the volatility correlations between two types of EPU of China and global oil price, the raw data of them are required. Based on the newspaper information related to fiscal and monetary policy, Baker et al. (2016) build a comprehensive EPU index for major economies, which has been widely accepted by researchers in this field. However, Huang and Luk (2020) point out this EPU index might not apply to China, and then establish a new EPU index system using the uncertainty information of Chinese mainland newspaper, which consists of the four types of economic policyfiscal policy, trade policy, exchange rate and capital account policy, and monetary policy. Here, the second index is used since our research focus on China, which can be accessed at https://economicpolicyuncertaintyinchina.weebly.com/. For the global oil price, three indicators are usually mentioned in relevant researches including WTI (West Texas Intermediate) oil price, Brent oil price, and Dubai oil price (Cheng and Cao 2019). Here, we choose to use the WTI oil price for the following two reasons: first, this research aims at providing valuable reference for different global market participants, and WTI is more appreciated by risk managers and market participants because of the active oil futures contract trade in New York Mercantile Exchange (You et al. 2017); second, the WTI oil price was usually regarded as the benchmark price in the international oil market and has been widely used in previous researches related to Chinese market ${ }^{2}$ (e.g., Sun et al. 2020; Zhu et al. 2021). The raw data of WTI oil price is collected from the open-accessed website: https://www.investing.com. Since China gradually synchronized its refined oil price with international refined oil price after entering twenty-first century (Kim et al. 2017), and the policy uncertainty data is disclosed from 2000 January, our research uses the monthly data from January 2000 to August 2020.

After collecting the raw data of WTI oil price, FPU and MPU index, we first calculate the returns of them, i.e., the first-order differences of their logs (Cheng et al. 2019). The

\footnotetext{
${ }^{2}$ Since the twenty-first century, the Brent oil price has consistent fluctuation trend with the WTI oil price at the most time. Due to space limitation, we just report the WTI-EPU volatility correlation results in the text, while that of Brent oil price is available upon request.
}

returns of them have been drawn in the following Fig. 1, from which significant fluctuation can be witnessed in 2020 and even larger than the 2008 global financial crisis! Since the positive and negative oil price returns separately represent the upward and downward oil price change, all samples can be divided into two different groups, namely "oil price increase group" and "oil price decrease group" (Herrera et al. 2015; Mork 1989). Previous literature has found that the squared return $\left(\left(\operatorname{lnP}_{\mathrm{t}}-\ln \mathrm{P}_{\mathrm{t}-1}\right)^{2}\right)$ can be used to estimate the actual unobserved volatility (Guhathakurta et al. 2020; Pan et al. 2017); it is employed in this research to represent the volatility of three variables.

The descriptive statistics of three volatilities is reported in Table 1, from which their basic statistical characteristics can be partly summarized as follows. First, the average WTI volatility of all sample and two oil price change groups are respectively $0.0126,0.0165$, and 0.0094 . The downward volatility of WTI oil price is significantly larger than its upward volatility, which implies that the decrease of oil price is more violent in general. Second, the standard deviations of two types of policy uncertainties are obviously larger than WTI volatility, which implies that the FPU/MPU volatilities are more violent than WTI volatility. Third, the skewness of all three variables is positive and the kurtosis of them is larger than 3, which means that they are all leptokurtic distributed. Lastly, the results of the Jarque-Bera tests show that all volatilities strongly reject the null hypothesis of normal distribution.

\section{Methodology}

To empirically test the asymmetric volatility correlations between WTI oil price and China's FPU/MPU in different time scales, a methodology mainly consists of two steps is established.

For the first step, the wavelet transformation approach is employed to decompose entire series into five time scales. Generally speaking, there are two types of wavelet transformation approach including continuous wavelet transform and discrete wavelet transform. Since the former will lead to information redundancy (Sun et al. 2020), the maximal overlap discrete wavelet transform (MODWT) is employed here to enhance the estimation efficiency. To be specific, any time function $\mathrm{X}(\mathrm{t}) \in \mathrm{L}^{2}(\mathrm{R})$ can be represented as a sequence of projections by a father and a mother wavelets, and then the longscale smooth components are represented by the father wavelets integrating to 1 and deviations from the smooth components are represented by the mother wavelets integrating to 0 . The scaling coefficients are generated by the father wavelets, whereas the differencing coefficients are generated by the mother wavelets.

In the first stage, multi-resolution analysis decomposes the original time series $X(\mathrm{t})$ into high-frequency components $H_{1}$ 
Fig. 1 Returns of WTI and China's FPU and MPU from January 2000 to August 2020

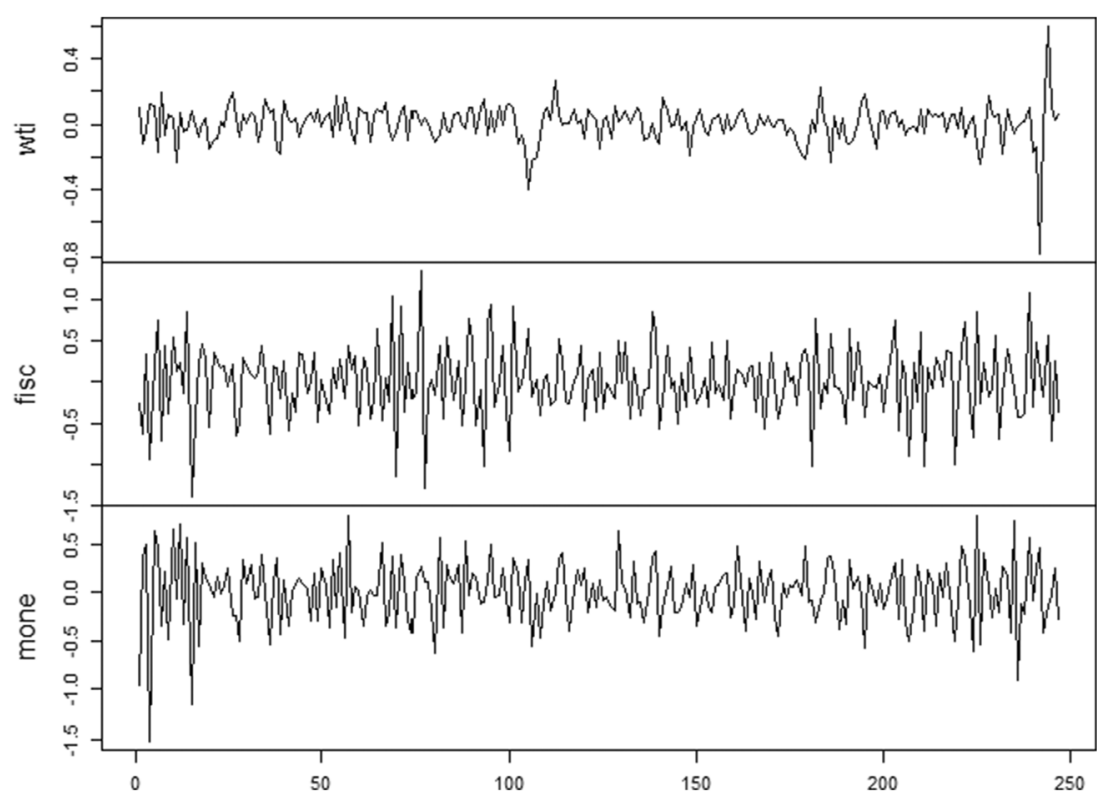

and low-frequency components $L_{1}$. Then, the high-frequency component $H_{1}$ is kept while the low-frequency component $L_{1}$ is decomposed into a high-frequency component $\mathrm{H}_{2}$ and a low-frequency component $L_{2}$ (Gençay et al. 2002). By this analogy, the original time series can be decomposed as:

$X(t)=H_{1}+L_{1}=H_{1}+H_{2}+L_{2}=\ldots=\sum_{i=1}^{n} H i+L_{n}$

After being processed, the time series is finally decomposed into several orderly scales, which respectively are at $2^{1}-2^{2}, 2^{2}-2^{3}, 2^{3}-2^{4}, 2^{4}-2^{5}$, and so on (Gupta et al. 2018).

For the second step, the VAR model is established and the Bayesian estimation approach is employed to estimate the VAR parameters. The VAR approach primarily bypasses the need for structural modeling by treating each endogenous variable in the system as a function of the lagged values of all of

Table 1 Descriptive statistics of all volatilities

\begin{tabular}{llllll}
\hline Statistics & WTI & W-L & W-H & FPU & MPU \\
\hline Mean & 0.0126 & 0.0165 & 0.0094 & 0.1942 & 0.1085 \\
Median & 0.0041 & 0.0045 & 0.0039 & 0.0693 & 0.0419 \\
Max & 0.6113 & 0.6113 & 0.3549 & 1.9503 & 2.3168 \\
Min & 0.0000 & 0.0000 & 0.0000 & 0.0000 & 0.0000 \\
Std. dev & 0.0465 & 0.0607 & 0.0311 & 0.3048 & 0.2090 \\
Skewness & 10.3469 & 8.7656 & 9.9249 & 2.9209 & 6.2192 \\
Kurtosis & 119.7679 & 82.0930 & 106.2581 & 10.1558 & 54.2162 \\
JB-stats & 0.0000 & 0.0000 & 0.0000 & 0.0000 & 0.0000 \\
$N$ & 247 & 109 & 138 & 247 & 247 \\
\hline
\end{tabular}

the endogenous variables (Sims 1980; Swamy 2020). A simple mathematical representation of a basic VAR model is

$Y_{t}=\alpha_{1} Y_{t-1}+\alpha_{2} Y_{t-2}+\ldots+\alpha_{n} Y_{t-n}+\varepsilon_{t}$

where $Y_{\mathrm{t}}$ is the endogenous variables of our research including WTI, FPU, and MPU volatility; $n$ is the lag period; $\alpha_{1}, \alpha_{2}, \ldots, \alpha_{\mathrm{n}}$ and $\beta$ are the corresponding coefficients to be estimated separately; and $\varepsilon_{\mathrm{t}}$ is a noise vector that may be contemporaneously correlated but are uncorrelated with all the right-hand side variables.

In recently years, the parametric estimation method such as Bayesian method has been widely used in macroeconomic time series analysis (e.g., Mao and Zhang 2018). Bayesian estimators using a certain type of noninformative priors showed higher accuracies than the other Bayesian estimators in simulated experiments (Ni and Sun 2005). For these reasons, the full Bayesian shrinkage method using noninformative priors is employed to estimate the VAR parameters. Since the model with the smallest AIC (Akaike information criterion) has the best fitting effect, the best lags are automatically determined in each time scale.

\section{Empirical results}

\section{Different time scales decomposition}

After two oil price change groups are determined, the MODWT method is adopted to decompose the entire time series into five time scales. Specifically speaking, the time spans at scale 1 to scale 5 corresponding to 2-4 months, 4-8 months, 8-16 months, 16-32 months, and 32+ months, 
respectively. The entire time series and corresponding subsequences in two oil price changes groups have been exhibited in the Figs. 2 and 3.

In the oil price decrease group, the obvious volatility of downward WTI oil price mainly appears in 2008 and 2020, which corresponds to the global financial crisis and recent economic recessions when the global oil market was hit hard. When the WTI oil price volatility keeps at a stable natural level at the most time, two types of EPU volatility of China have obvious fluctuant trend. With the expansion of the time scales, the WTI oil price volatility changes from stationary to fluctuant differently, while the FPU and MPU volatilities fluctuate violently in the short term and have obvious changing trend in the long term. In addition, it is worth noting that the obvious MPU volatility slightly lags behind the FPU volatility, especially in the short and middle term, which implies that the volatility of FPU will significantly transfer to MPU in China when global oil price is decreasing.

In the oil price increase group, similar peaks of WTI volatility also appear in 2008 and 2020, and several smaller volatilities occasionally exist, which implies that global oil price experiences more upward shock than downward shock. In addition, unlike the oil price decrease group, the volatility of two types of policy uncertainty is inconsistent for the most time, the FPU volatility of China still fluctuates violently, while the MPU volatility of China is rather stable (around 0) except for the obvious volatility in the early stage of twenty- first century in all five time scales, which is consistent with the positive fiscal policy and prudent monetary policy of China (Liu et al. 2021).

Totally speaking, it is obvious that the volatility of WTI, FPU, and MPU all has different changing trends in different oil price change directions and different time scales; thus, their correlations might be more complicated in various conditions. For example, the WTI-MPU volatility is mostly synchronous in the oil price decrease group, while it seems that their connection in the oil price decrease group is relatively unclear. Therefore, our work to investigate their diversified correlations is of great necessity.

\section{Volatility correlations in different time scales}

On the basis of group division and scale decomposition as above, the last step is to investigate the volatility correlations in different status. According to the AIC results listed in the Table 2, the best lag periods are determined separately. In the oil price decrease group, the best lag periods of five scales are 1-2-3-1-2 and 3-2-2-1-1, respectively.

Then the next step is to pursue the VAR model. In this research, the Phillips-Perron (PP) unit root test is applied to test the stationarity of all variables in two groups and five scales, and results of which have been listed in Table 3. It can be noticed that all but scale 5 of both groups passes the stationary test, which is also in line with the result of Sun et al.
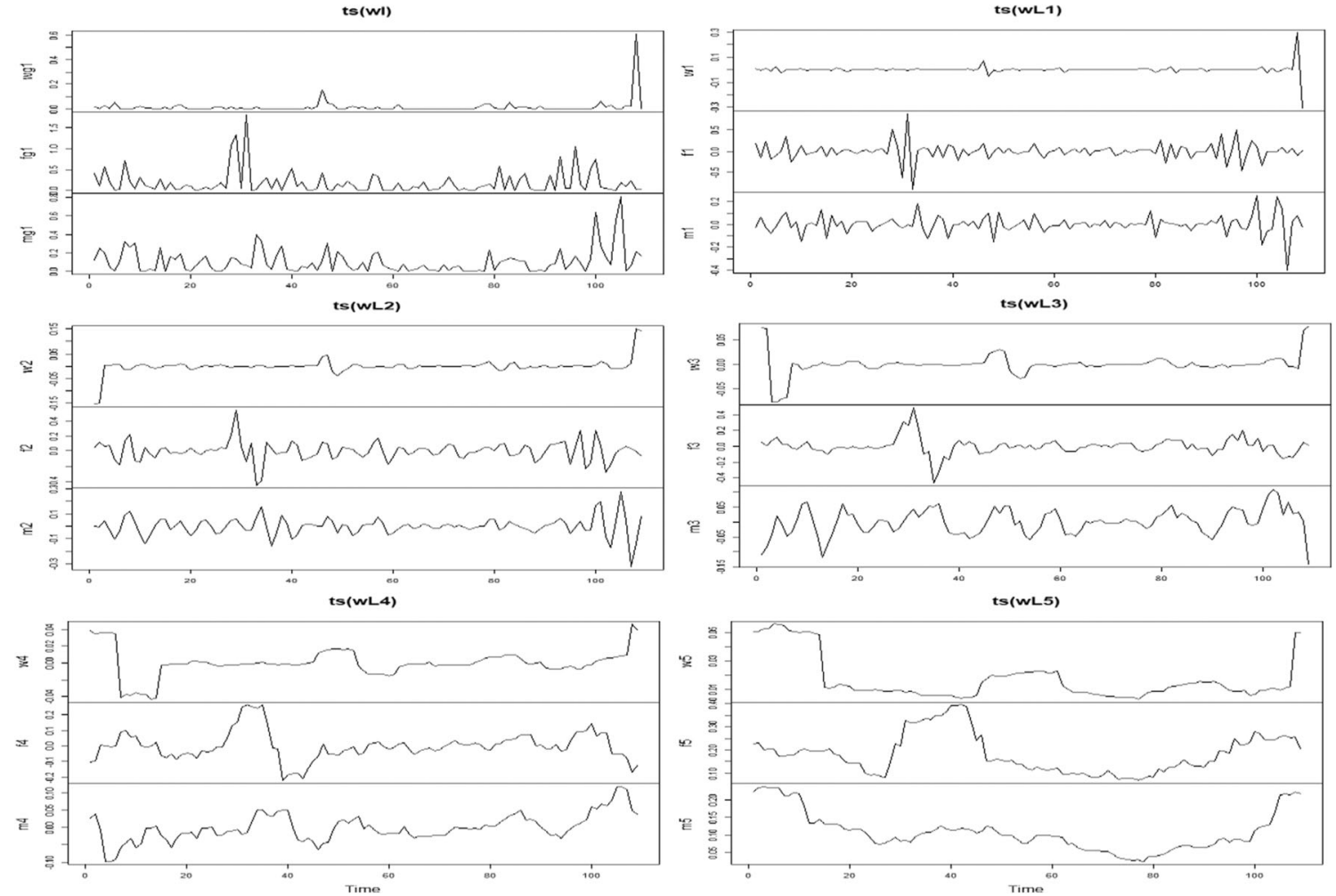

Fig. 2 Time scales decomposition in the oil price decrease group 
ts(wh)

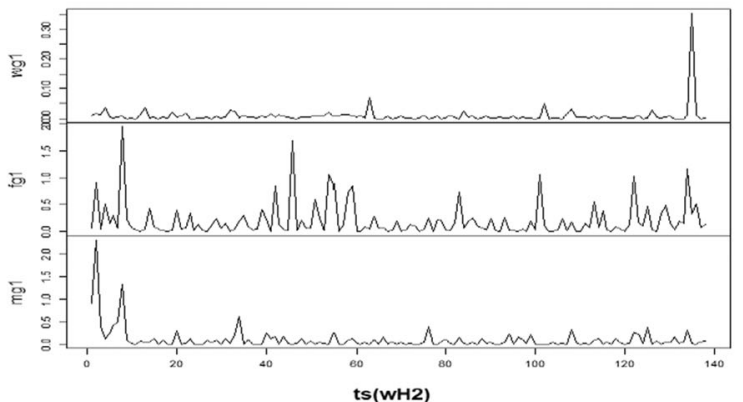

ts(wH2)
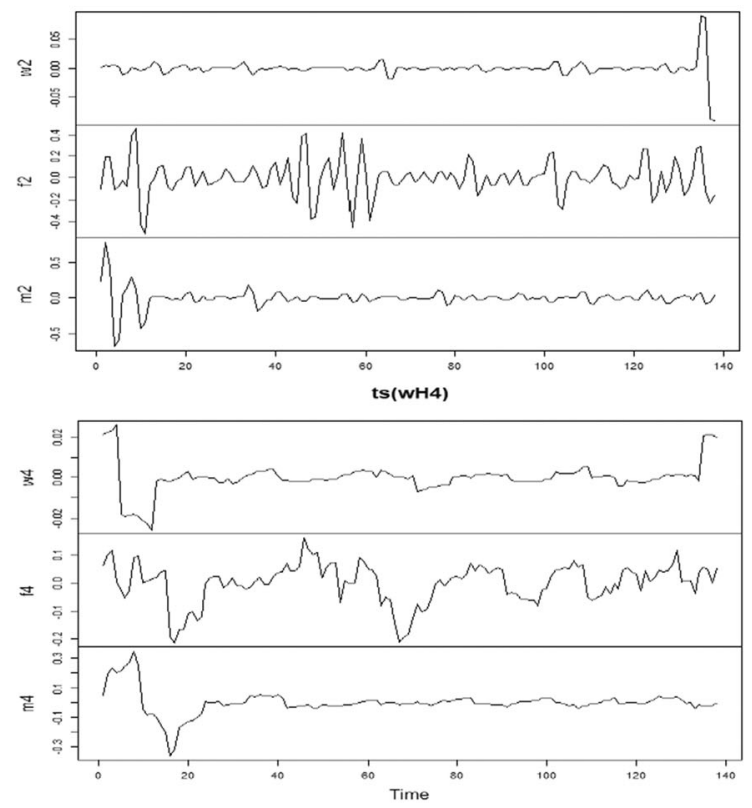

Fig. 3 Time scales decomposition in the oil price increase group

(2020). Therefore, our VAR model is conducted in the scales $1-4$, and the specific volatility correlations between WTI and FPU/MPU are displayed in Table 4 and Table 5, which are meanwhile corresponding to the aforementioned two figures.

In the scale 1, the WTI, FPU, and MPU volatilities are all negatively related to their own lags, and all three volatilities

Table 2 AIC of different lags

\begin{tabular}{lllll}
\hline AIC & Best lag & Lag 1 & Lag 2 & Lag 3 \\
\hline wL1 & 1 & $\mathbf{- 1 0 4 4 . 5 3 5}$ & -1037.4435 & -1023.2898 \\
wL2 & 2 & -1135.327 & $\mathbf{- 1 3 1 3 . 0 5 2}$ & -1293.610 \\
wL3 & 3 & -1499.461 & -1506.906 & $-\mathbf{1 5 3 0 . 5 6 0}$ \\
wL4 & 1 & $-\mathbf{1 8 7 5 . 5 9 0}$ & -1866.316 & -1857.915 \\
wL5 & 2 & -2268.427 & $\mathbf{- 2 2 6 3 . 0 4 5}$ & -2234.308 \\
wH1 & 3 & -1390.656 & -1391.154 & $-\mathbf{1 3 9 8 . 3 8}$ \\
wH2 & 2 & -1463.165 & $\mathbf{- 1 7 2 1 . 2 3 9}$ & -1727.835 \\
wH3 & 2 & -2039.513 & $-\mathbf{2 0 5 1 . 6 8 4}$ & -2048.846 \\
wH4 & 1 & $-\mathbf{2 4 9 2 . 3 5 1}$ & -2482.651 & -2480.120 \\
wH5 & 1 & $-\mathbf{2 9 8 6 . 6 7 6}$ & -2984.043 & -2970.478 \\
\hline
\end{tabular}

$t s(w H 1)$
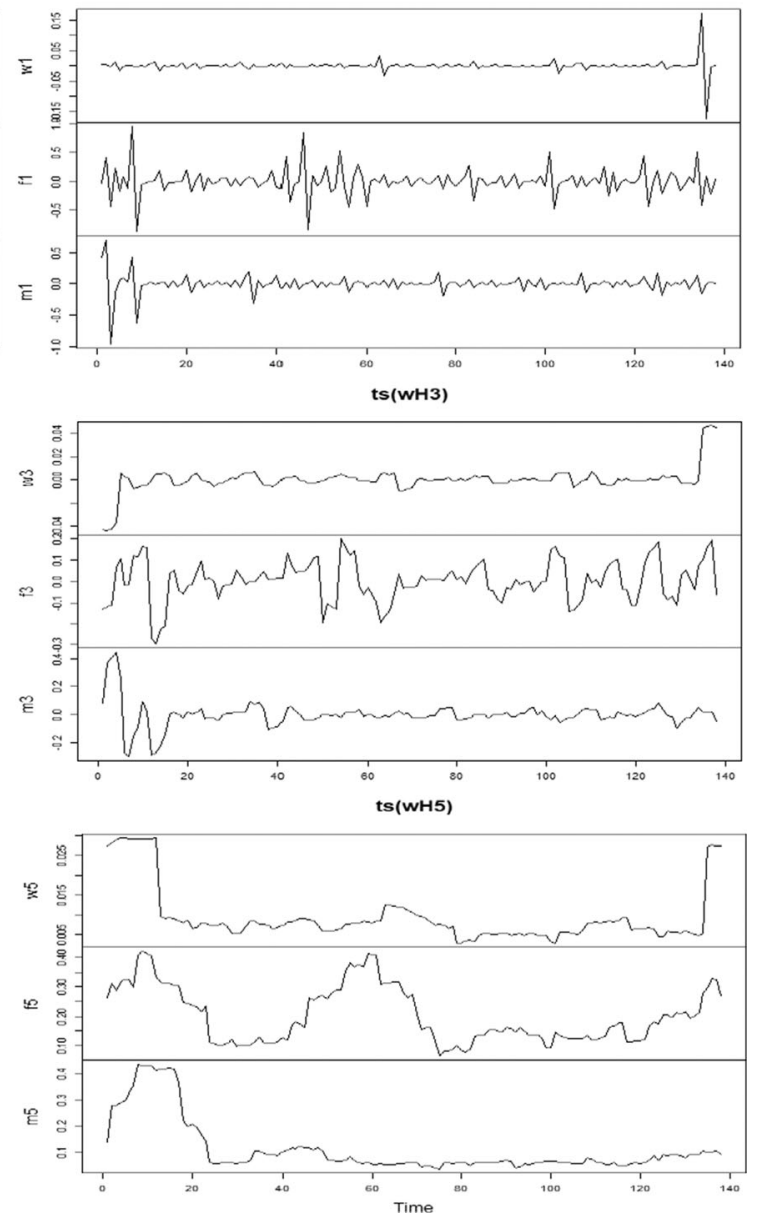

are independent of each other in the short term. In the scale 2, the WTI volatility's response to its lags changes to positive while that of FPU and MPU volatility are still negative with the coefficients of -0.3994 and -0.7954 in the 2-period lag. Besides, the bidirectional influence between WTI and MPU volatilities is both significantly negative in the 1-period lags, with the coefficients of -0.1100 and -0.4254 at the significance of $1 \%$. In the scale 3 , all three volatilities are positively related to their 1period lags with the coefficients of $0.9687,0.5821$, and 0.8066 at the significance of $1 \%$. Besides, the MPU volatility will positively respond to WTI volatility with the coefficient of 0.3275 . In the scale 4 , all three volatilities are significantly positively related to their 1-period lags, while the correlations between WTI and FPU/ MPU volatility are always insignificant.

Several findings can be acquired after comparing the WTIFPU/MPU correlations in different time scales of oil price decrease group. Firstly, the volatility correlation between WTI and China's FPU is always insignificant, which implies that China's fiscal policy and downward global oil price volatility are mutually independent to some extent. Secondly, the impact of WTI volatility on MPU volatility is significantly negative in the middle term (scale 2, 4-8 months) while 
Table 3 Results of PP unit root test for volatility series in five time scales

\begin{tabular}{|c|c|c|c|c|c|c|}
\hline Oil price & Variable & Scale 1 & Scale 2 & Scale 3 & Scale 4 & Scale 5 \\
\hline \multirow[t]{3}{*}{ Decrease } & W & $-21.4508 * * *$ & $-5.0004 * * *$ & $-5.5034 * * *$ & $-3.3933 * *$ & -1.9164 \\
\hline & $\mathrm{F}$ & $-41.3850 * * *$ & $-8.8256 * * *$ & $-3.6921 * *$ & $-3.4375 * *$ & -2.0799 \\
\hline & M & $-58.6063 * * *$ & $-15.5151 * * *$ & $-3.6380 * * *$ & $-3.0603 * *$ & -1.5971 \\
\hline \multirow[t]{3}{*}{ Increase } & W & $-101.5920 * * *$ & $-4.4759 * * *$ & $-3.3604 * *$ & $-4.2697 * * *$ & -2.2373 \\
\hline & $\mathrm{F}$ & $-68.0989 * * *$ & $-27.5227 * * *$ & $-5.3983 * * *$ & $-4.1008 * * *$ & -1.9268 \\
\hline & M & $-36.0294 * * *$ & $-10.4622 * * *$ & $-3.6759 * * *$ & $-3.2150 * *$ & -1.7788 \\
\hline
\end{tabular}

changes to positive in the middle-long term (scale 3, 8-16 months). On the contrary, the impact of MPU volatility on WTI volatility is significantly negative in the middle term (scale 2). Lastly, the correlations between three volatilities and their own lags are all significantly negative in the short term, which implies the existence of the self-correction effect in the short term. With the extension of the period, this selfcorrelation changes to positive in the middle term and long term.

In the oil price increase group, the volatility correlations between WTI and FPU or MPU are always insignificant in scale 1 to scale 3, which implies that the connections between upward global oil price volatility and China's policy uncertainty are relatively weak in the short term and the middle term. In the meantime, the responses of three volatilities to their own lags gradually change from negative to positive and are always significant. In the scale 4 , the WTI volatility is positively affected by FPU volatility's 1-period lag and negatively affected by MPU's 1- period lag with the coefficients of 0.0116 and -0.0132 , respectively. Conversely, the volatility impact of WTI's lag on FPU is insignificant while that on MPU is significantly positive with the coefficient of 1.0830 .

Similarly, some rules can be summarized from the results in different scales of oil price increase group. Firstly, the volatility responses of MPU to WTI are only significantly positive in the long term (scale 4, 16-32 months), while that of FPU is always insignificant in all time scales. That is to say, China's monetary policy will gradually respond to upward global oil price fluctuation. Secondly, the FPU and MPU volatility of China will influence global oil price volatility in the long term, which is consistent with the findings of Sun et al. (2020). Moreover, we find that the long-term volatility impact of FPU and MPU on WTI is opposite. Lastly and like the above group, the correlations between three volatilities and their own lags are significantly negative in the short term and gradually change to positive in the middle and long term.

Table 4 Volatility correlations in oil price decrease group

\begin{tabular}{|c|c|c|c|c|c|c|}
\hline Lags & W1 & $\mathrm{F} 1$ & M1 & W2 & $\mathrm{F} 2$ & M2 \\
\hline $\mathrm{WTI}_{-1}$ & $-0.8856 * * *$ & -0.1096 & 0.0893 & $0.6340 * * *$ & -0.1217 & $-0.4254 * * *$ \\
\hline $\mathrm{FPU}_{-1}$ & 0.0066 & $-0.5311 * * *$ & -0.0283 & 0.0195 & $0.2506 * * *$ & 0.0011 \\
\hline $\mathrm{MPU}_{-1}$ & 0.0010 & -0.0104 & $-0.2184 * *$ & $-0.1100 * * *$ & 0.0393 & $0.4668 * * *$ \\
\hline $\mathrm{WTI}_{-2}$ & & & & $-0.3634 * * *$ & -0.1593 & $0.1833 *$ \\
\hline $\mathrm{FPU}_{-2}$ & & & & -0.0034 & $-0.3994 * * *$ & -0.0307 \\
\hline $\mathrm{MPU}_{-2}$ & & & & 0.0206 & -0.0177 & $-0.7954 * * *$ \\
\hline Lags & W3 & F3 & M3 & W4 & $\mathrm{F} 4$ & M4 \\
\hline WTI-1 $_{-1}$ & $0.9687 * * *$ & 0.0333 & $0.3275 * *$ & $0.9569 * * *$ & 0.0023 & 0.0980 \\
\hline $\mathrm{FPU}_{-1}$ & -0.0045 & $0.5821 * * *$ & -0.0435 & 0.0010 & $0.9177 * * *$ & $0.0493 * * *$ \\
\hline $\mathrm{MPU}_{-1}$ & 0.0236 & 0.0166 & $0.8066 * * *$ & 0.0009 & -0.0521 & $0.9374 * * *$ \\
\hline WTI-2 $_{-2}$ & -0.0459 & 0.3337 & $0.2427 *$ & & & \\
\hline $\mathrm{FPU}_{-2}$ & 0.0039 & -0.0326 & 0.0163 & & & \\
\hline $\mathrm{MPU}_{-2}$ & -0.0198 & 0.0779 & -0.0250 & & & \\
\hline $\mathrm{WTI}_{-3}$ & -0.0156 & -0.0294 & 0.1154 & & & \\
\hline $\mathrm{FPU}_{-3}$ & -0.0014 & -0.0306 & 0.0307 & & & \\
\hline $\mathrm{MPU}_{-3}$ & -0.0042 & $-0.4067 *$ & $-0.3719 * * *$ & & & \\
\hline
\end{tabular}

Notes: $* * *, * *$, and $*$ denote rejection of null hypothesis at $1 \%, 5 \%$, and $10 \%$ significance level, respectively 
Table 5 Volatility correlations in oil price increase group

\begin{tabular}{|c|c|c|c|c|c|c|}
\hline Lags & W1 & $\mathrm{F} 1$ & M1 & W2 & $\mathrm{F} 2$ & M2 \\
\hline WTI $_{-1}$ & $-0.2803 * * *$ & 0.0598 & 0.0195 & $0.4799 * * *$ & 0.3157 & 0.0029 \\
\hline $\mathrm{FPU}_{-1}$ & 0.0010 & $-0.4899 * * *$ & 0.0420 & 0.0010 & $0.3438 * * *$ & 0.0016 \\
\hline MPU $_{-1}$ & 0.0097 & -0.0623 & $-0.4326 * * *$ & 0.0005 & 0.0119 & $0.5633 * * *$ \\
\hline $\mathrm{WTI}_{-2}$ & $-0.2138 * * *$ & 0.0151 & -0.0285 & $-0.5301 * * *$ & -0.1353 & 0.1133 \\
\hline $\mathrm{FPU}_{-2}$ & -0.0001 & $-0.3585 * * *$ & -0.0097 & -0.0015 & $-0.6541 * * *$ & -0.0370 \\
\hline $\mathrm{MPU}_{-2}$ & 0.0089 & 0.0664 & $-0.1316 * *$ & 0.0033 & $0.2257 * * *$ & $-0.4416 * * *$ \\
\hline $\mathrm{WTI}_{-3}$ & $-0.1669 * * *$ & -0.0824 & 0.0584 & & & \\
\hline $\mathrm{FPU}_{-3}$ & 0.0000 & $-0.2248 * * *$ & 0.0014 & & & \\
\hline $\mathrm{MPU}_{-3}$ & 0.0007 & 0.0675 & $-0.1254 * *$ & & & \\
\hline Lags & W3 & F3 & M3 & W4 & F4 & M4 \\
\hline $\mathrm{WTI}_{-1}$ & $0.9912 * * *$ & 0.1871 & -0.1072 & $0.7908 * * *$ & -0.2406 & $1.0830 * * *$ \\
\hline $\mathrm{FPU}_{-1}$ & 0.0000 & $0.8535 * * *$ & 0.0373 & $0.0116 * *$ & $0.7502 * * *$ & $-0.1628 * * *$ \\
\hline $\mathrm{MPU}_{-1}$ & 0.0029 & -0.0647 & $0.8690 * * *$ & $-0.0132 * * *$ & $0.0802 *$ & $0.9467 * * *$ \\
\hline $\mathrm{WTI}_{-2}$ & $-0.1065 * *$ & -0.2666 & -0.2474 & & & \\
\hline $\mathrm{FPU}_{-2}$ & -0.0010 & -0.0685 & -0.0662 & & & \\
\hline $\mathrm{MPU}_{-2}$ & -0.0040 & 0.0417 & $-0.1247 *$ & & & \\
\hline
\end{tabular}

Notes: $* * * * *$, and $*$ denote rejection of null hypothesis at $1 \%, 5 \%$, and $10 \%$ significance level, respectively

When comparing the results in two oil price change groups, some interesting differences between them can be noticed. First, the volatility correlation between WTI and China's EPU mainly reflects on the MPU, while the FPU-WTI volatility correlation is much weaker. To be specific, the volatility correlation between China's FPU and WTI is always insignificant when oil price is decreasing, while in the oil price increase group, the FPU volatility's impact on WTI volatility is significantly positive in the long term (16-32 months). Secondly, the volatility response of China's MPU to WTI is significantly negative in the middle term (4-8 months) and positive in the middle-long term (8-16 months) when oil price is reducing, but when oil price is increasing, the positive response only reflects in the long term (16-32 months). Lastly, there is a significant negative correlation between China's MPU volatility 1-period lag and WTI volatility, and this correlation is significant and stronger in the middle term (4-8 months) when oil price is decreasing, while reflects in the long term (16-32 months) when oil price is increasing.

\section{Conclusions}

The connection between oil price and different types of policy uncertainty is attracting the attentions of more and more researchers, investors, and policy-makers, especially when the global economy is experiencing a great recession caused by oil price war and COVID-19 epidemic in 2020. As the second largest oil consumer in the world and important drive force of global economic recovery, it is of great value to figure out how global oil price interacts with EPU of China. Moreover, the impact of oil price shock is usually asymmetric and varies with different time scales, and different market participants care about the oil price fluctuation and macroeconomic policies in different conditions. In this context, using the monthly data of WTI oil price and China's two types of EPU (FPU and MPU) indices over the period January 2000 to August 2020, this paper attempts to investigate the volatility correlations between global oil price and China's two types of EPU in different oil price change groups and time scales.

Using the MODWT model and VAR model with full Bayesian estimation, our empirical results verify that the volatility correlations between WTI oil price and EPU of China are obviously asymmetric and varied in different time scales, which can be an important expansion of latest researches such as Lin and Bai (2021) and Sun et al. (2020). When comparing the results in different types of EPU, different oil price change directions, and different time scales, several conclusions are naturally obtained. Firstly, significant correlation between WTI volatility's 1-period lag and MPU volatility is witnessed in both oil price change groups, which is consistent with the findings of Kim et al. (2017) that oil shock is important source of volatility of China's interest rate. However, the correlation between China's FPU and WTI volatility is much weaker. Secondly, when global oil price is decreasing, China's MPU volatility is significantly correlated to WTI volatility's 1-period lag in the short-middle and middle-long term (4-16 months), which means that downward oil price volatility tends to have direct and relatively quick connection with China's monetary policy, echoing the 
findings of Cheng et al. (2019) that Chinese government tends to reboot the macroeconomy with active monetary policies when facing negative oil shock. However, the significant oil price-EPU volatility correlation appears in the long term (1632 months) of the oil price increase period, which implies Chinese government tends to adjust the fiscal and monetary policy to cope with long-term and upward oil price fluctuation. Lastly, the lags of China's FPU and MPU volatility are significantly correlated with upward WTI volatility in the long term, which verifies the long-term interaction between EPU of China and WTI oil price found by Sun et al. (2020).

In summary, this research exposes the asymmetric and multi-scale volatility correlations between global oil price and two types of EPU in China, which largely enhance the understanding of how China's fiscal and monetary policies interact with external oil price shock, as well as how to adjust the portfolio of global investor in different macroeconomic backgrounds. There is no doubt that there still have rooms for our research to expand, for example, we only divide the oil price change into different directions, while this symmetry might be more complicated and requires deeper study. Hopefully, our further researches can make further exploration on this question.

Author contribution QJ collected the data, pursued the empirical tests, and was a major contributor in writing the manuscript. SC provided the initial idea, patient guidance, and revision suggestions. YC provided important modification suggestions. ZW provided important language assistance. All authors read and approved the final manuscript.

Funding This work is financially supported by the National Natural Science Foundation of China (71373246), Key Projects of Philosophy and Social Sciences Research, Ministry of Education of China (15ZD014), Natural Science Foundation of Hubei Province (2015CFB497), as well as the Fundamental Research Funds for the Central Universities, China University of Geosciences, (Wuhan) to Shougeng $\mathrm{Hu}$.

Data availability The datasets used are available in the https:// economicpolicyuncertaintyinchina.weebly.com/ and https://www. investing.com.

\section{Declarations}

Ethics approval and consent to participate Not applicable.

Consent to publish Not applicable.

Competing interests The authors declare no competing interests.

\section{References}

Akinsola MO, Odhiambo NM (2020) Asymmetric effect of oil price on economic growth: panel analysis of low-income oil-importing countries. Energy Rep 6:1057-1066. https://doi.org/10.1016/j. egyr.2020.04.023

Antonakakis N, Chatziantoniou I, Filis G (2014) Dynamic spillovers of oil price shocks and economic policy uncertainty. Energy Econ 44: 433-447. https://doi.org/10.1016/j.eneco.2014.05.007

Baker SR, Bloom N, Davis SJ (2016) Measuring Economic Policy Uncertainty*. Q J Econ 131:1593-1636. https://doi.org/10.1093/ qje/qjw024

Bloom N (2009) The Impact of Uncertainty Shocks. Econometrica 77: 623-685. https://doi.org/10.3982/ecta6248

Chen X, Sun X, Li J (2020) How does economic policy uncertainty react to oil price shocks? A multi-scale perspective. Appl Econ Lett 27: 188-193. https://doi.org/10.1080/13504851.2019.1610704

Cheng S, Cao Y (2019) On the relation between global food and crude oil prices: an empirical investigation in a nonlinear framework. Energy Econ 81:422-432. https://doi.org/10.1016/j.eneco.2019.04.007

Cheng D, Shi X, Yu J, Zhang D (2019) How does the Chinese economy react to uncertainty in international crude oil prices? Int Rev Econ Financ 64:147-164. https://doi.org/10.1016/j.iref.2019.05.008

Das D, Kannadhasan M (2020) The asymmetric oil price and policy uncertainty shock exposure of emerging market sectoral equity returns: a quantile regression approach. Int Rev Econ Financ 69: 563-581. https://doi.org/10.1016/j.iref.2020.06.013

El Anshasy AA, Bradley MD (2012) Oil prices and the fiscal policy response in oil-exporting countries. J Policy Model 34:605-620. https://doi.org/10.1016/j.jpolmod.2011.08.021

Gençay R, Gençay R, Selcuk F, Whitcher BJ (2002) An introduction to wavelets and other filtering methods in finance and economics. Elsevier

Guhathakurta K, Dash SR, Maitra D (2020) Period specific volatility spillover based connectedness between oil and other commodity prices and their portfolio implications. Energy Econ 85:104566. https://doi.org/10.1016/j.eneco.2019.104566

Gupta S, Das D, Hasim H, Tiwari AK (2018) The dynamic relationship between stock returns and trading volume revisited: a MODWTVAR approach Financ Res Lett 27:91-98. https://doi.org/10.1016/ j.frl.2018.02.018

Hamilton JD (1983) Oil and the Macroeconomy since World War II. J Polit Econ 91:228-248. https://doi.org/10.1086/261140

Herrera AM, Lagalo LG, Wada T (2015) Asymmetries in the response of economic activity to oil price increases and decreases? J Int Money Financ 50:108-133. https://doi.org/10.1016/j.jimonfin.2014.09.004

Huang Y, Luk P (2020) Measuring economic policy uncertainty in China. China Econ Rev 59:101367. https://doi.org/10.1016/j.chieco.2019. 101367

Huang S, An H, Gao X, Hao X (2016) Unveiling heterogeneities of relations between the entire oil-stock interaction and its components across time scales. Energy Econ 59:70-80. https://doi.org/10.1016/j. eneco.2016.07.025

Jarrett U, Mohaddes K, Mohtadi H (2019) Oil price volatility, financial institutions and economic growth. Energy Policy 126:131-144. https://doi.org/10.1016/j.enpol.2018.10.068

Jiang Q, Cheng S (2021) How the fiscal and monetary policy uncertainty of China respond to global oil price volatility: a multi-regime-onscale approach. Res Policy 72:102121. https://doi.org/10.1016/j. resourpol.2021.102121

Jiang Q, Yang S, Tang P, Bao L (2020) Promoting the polluters? The competing objectives of energy efficiency, pollutant emissions, and economic performance in Chinese municipalities. Energy Res Soc Sci 61:101365. https://doi.org/10.1016/j.erss.2019.101365

Jones PM, Olson E (2013) The time-varying correlation between uncertainty, output, and inflation: evidence from a DCC-GARCH model. Econ Lett 118:33-37. https://doi.org/10.1016/j.econlet.2012.09.012

Kang W, Ratti RA (2013) Structural oil price shocks and policy uncertainty. Econ Model 35:314-319. https://doi.org/10.1016/j.econmod. 2013.07.025 
Kang W, Ratti RA (2015) Oil shocks, policy uncertainty and stock returns in China. Econ Transit 23:657-676. https://doi.org/10.1111/ecot. 12062

Kang W, Ratti RA, Vespignani JL (2017) Oil price shocks and policy uncertainty: new evidence on the effects of US and non-US oil production. Energy Econ 66:536-546. https://doi.org/10.1016/j. eneco.2017.01.027

Khraief N, Shahbaz M, Mahalik MK, Bhattacharya M (2021) Movements of oil prices and exchange rates in China and India: new evidence from wavelet-based, non-linear, autoregressive distributed lag estimations. Physica A: Statistical Mechanics and its Applications 563:125423. https://doi.org/10.1016/j.physa.2020. 125423

Kim WJ, Hammoudeh S, Hyun JS, Gupta R (2017) Oil price shocks and China's economy: reactions of the monetary policy to oil price shocks. Energy Econ 62:61-69. https://doi.org/10.1016/j.eneco. 2016.12.007

Kocaarslan B, Soytas MA, Soytas U (2020) The asymmetric impact of oil prices, interest rates and oil price uncertainty on unemployment in the US. Energy Econ 86:104625. https://doi.org/10.1016/j.eneco. 2019.104625

Koh WC (2017) Oil price shocks and macroeconomic adjustments in oilexporting countries. IEEP 14:187-210. https://doi.org/10.1007/ s10368-015-0333-z

Lin B, Bai R (2021) Oil prices and economic policy uncertainty: evidence from global, oil importers, and exporters' perspective. Res Int Bus Financ 56:101357. https://doi.org/10.1016/j.ribaf.2020.101357

Liu J-Y, Lin S-M, Xia Y, Fan Y, Wu J (2015) A financial CGE model analysis: oil price shocks and monetary policy responses in China. Econ Model 51:534-543. https://doi.org/10.1016/j.econmod.2015. 08.025

Liu D, Sun W, Chang L (2021) Monetary-fiscal policy regime and macroeconomic dynamics in China. Econ Model 95:121-135. https:// doi.org/10.1016/j.econmod.2020.12.007

Maheu JM, Song Y, Yang Q (2020) Oil price shocks and economic growth: the volatility link. Int J Forecast 36:570-587. https://doi. org/10.1016/j.ijforecast.2019.07.008

Mao G, Zhang Z (2018) Stochastic tail index model for high frequency financial data with Bayesian analysis. J Econ 205:470-487. https:// doi.org/10.1016/j.jeconom.2018.03.019

Mei D, Zeng Q, Cao X, Diao X (2019) Uncertainty and oil volatility: new evidence. Physica A: Statistical Mechanics and its Applications 525: 155-163. https://doi.org/10.1016/j.physa.2019.03.043

Montoro C (2012) Oil shocks and optimal monetary policy. Macroecon Dyn 16:240-277

Mork K (1989) Oil and macroeconomy when prices go up and down: an extension of Hamilton's results. J Polit Econ 97:740-744. https:// doi.org/10.1086/261625

Naifar N, Shahzad SJH, Hammoudeh S (2020) Dynamic nonlinear impacts of oil price returns and financial uncertainties on credit risks of oil-exporting countries. Energy Econ 88:104747. https://doi.org/10. 1016/j.eneco.2020.104747

Ni S, Sun D (2005) Bayesian estimates for vector autoregressive models. J Bus Econ Stat 23:105-117. https://doi.org/10.1198/ 073500104000000622

Pan Z, Wang Y, Wu C, Yin L (2017) Oil price volatility and macroeconomic fundamentals: a regime switching GARCH-MIDAS model. J Empir Financ 43:130-142. https://doi.org/10.1016/j.jempfin.2017. 06.005

Peltzman S (2000) Prices rise faster than they fall. J Polit Econ 108:466502. https://doi.org/10.1086/262126

Peter Ferderer J (1996) Oil price volatility and the macroeconomy. J Macroecon 18:1-26. https://doi.org/10.1016/S0164-0704(96) 80001-2
Pieschacón A (2012) The value of fiscal discipline for oil-exporting countries. J Monet Econ 59:250-268. https://doi.org/10.1016/j.jmoneco. 2012.03.001

Qin M, Su C-W, Hao L-N, Tao R (2020) The stability of U.S. economic policy: does it really matter for oil price? Energy 198. https://doi.org/ 10.1016/j.energy.2020.117315

Reboredo JC, Ugolini A (2016) The impact of downward/upward oil price movements on metal prices. Res Policy 49:129-141. https:// doi.org/10.1016/j.resourpol.2016.05.006

Shangle A, Solaymani S (2020) Responses of monetary policies to oil price changes in Malaysia. Energy 200:117553. https://doi.org/10. 1016/j.energy.2020.117553

Shin Y, Yu B, Greenwood-Nimmo M (2014) Modelling asymmetric cointegration and dynamic multipliers in a nonlinear ARDL framework. In: Sickles RC, Horrace WC (eds) Festschrift in Honor of Peter Schmidt: Econometric Methods and Applications. Springer New York, New York, pp 281-314. https://doi.org/10.1007/978-14899-8008-3_9

Sims CA (1980) Macroeconomics and Reality. Econometrica 48:1-48. https://doi.org/10.2307/1912017

Sun X, Chen X, Wang J, Li J (2020) Multi-scale interactions between economic policy uncertainty and oil prices in time-frequency domains. N Am J Econ Finance:51. https://doi.org/10.1016/j.najef. 2018.10.002

Swamy V (2020) Macroeconomic transmission of Eurozone shocks to India - a mean-adjusted Bayesian VAR approach. Econ Anal Pol 68, 68:126, 126-150, 150. https://doi.org/10.1016/j.eap.2020.09. 008

Tang P, Jiang Q, Mi L (2021) One-vote veto: the threshold effect of environmental pollution in China's economic promotion tournament. Ecol Econ 185:107069. https://doi.org/10.1016/j.ecolecon. 2021.107069

Trung NB (2019) The spillover effects of US economic policy uncertainty on the global economy: a global VAR approach. N Am J Econ Finance 48:90-110. https://doi.org/10.1016/j.najef.2019.01.017

Uddin GS, Bekiros S, Ahmed A (2018) The nexus between geopolitical uncertainty and crude oil markets: an entropy-based wavelet analysis. Physica A: Statistical Mechanics and its Applications 495:30 39. https://doi.org/10.1016/j.physa.2017.12.025

van Eyden R, Difeto M, Gupta R, Wohar ME (2019) Oil price volatility and economic growth: evidence from advanced economies using more than a century's data. Appl Energy 233-234:612-621. https://doi.org/10.1016/j.apenergy.2018.10.049

Wei Y (2019) Oil price shocks, economic policy uncertainty and China's trade: a quantitative structural analysis. N Am J Econ Finance 48: 20-31. https://doi.org/10.1016/j.najef.2018.08.016

Xue W, Yilmazkuday H, Taylor JE (2020) The impact of China's fiscal and monetary policy responses to the great recession: an analysis of firm-level Chinese data. J Int Money Financ 101:102113. https:// doi.org/10.1016/j.jimonfin.2019.102113

Yang L (2019) Connectedness of economic policy uncertainty and oil price shocks in a time domain perspective. Energy Econ 80:219 233. https://doi.org/10.1016/j.eneco.2019.01.006

You W, Guo Y, Zhu H, Tang Y (2017) Oil price shocks, economic policy uncertainty and industry stock returns in China: asymmetric effects with quantile regression. Energy Econ 68:1-18. https://doi.org/10. 1016/j.eneco.2017.09.007

Zhang Y-J, Yan X-X (2020) The impact of US economic policy uncertainty on WTI crude oil returns in different time and frequency domains Int Rev Econ Financ 69:750-768. https://doi.org/10.1016/ j.iref.2020.04.001

Zhang D, Lei L, Ji Q, Kutan AM (2019) Economic policy uncertainty in the US and China and their impact on the global markets. Econ Model 79:47-56. https://doi.org/10.1016/j.econmod.2018.09.028 
Zhu H, Chen X (2019) Asymmetric effects of oil prices and exchange rates on China's industrial prices. Energy Econ 84:104551. https:// doi.org/10.1016/j.eneco.2019.104551

Zhu H, Chen W, Hau L, Chen Q (2021) Time-frequency connectedness of crude oil, economic policy uncertainty and Chinese commodity markets: evidence from rolling window analysis. N Am J Econ Finance 57:101447. https://doi.org/10.1016/j.najef.2021.101447

Publisher's note Springer Nature remains neutral with regard to jurisdictional claims in published maps and institutional affiliations. 